\title{
LIBRAS NA FORMAÇÃO DE PROFESSORES: O VÍDEO COMO FERRAMENTA DE AVALIAÇÃO DA APRENDIZAGEM
}

\section{LIBRAS IN TEACHER'S EDUCATION: THE VIDEO AS A LEARNING EVALUATION TOOL}

DOI: http://dx.doi.org/10.5965/1984317815012019217

Thiago Ramos de Albuquerque

Universidade Federal de Pernambuco

thiago.albuquerque1@gmail.com

Kátia Calligaris Rodrigues

Universidade Federal de Pernambuco kalligaris@gmail.com

Ernesto Arcenio Valdés Rodriguez

Universidade Federal de Pernambuco evrbr@yahoo.com.br

\section{RESUMO}

Este trabalho relata a análise de um conjunto de atividades didáticas de produção de vídeos em Língua Brasileira de Sinais (Libras) por estudantes de cursos de licenciatura do Núcleo de Formação Docente do Centro Acadêmico do Agreste da Universidade Federal de Pernambuco. De forma introdutória, trazemos algumas considerações sobre o lugar da Libras no contexto da educação superior no Brasil. Em seguida tratamos sobre avaliação e autorregulação no processo de ensino-aprendizagem (SILVA, 2007; PERRENOUD, 1999). Finalizando o referencial teórico, discorremos sobre aprendizagem móvel (BOTTENTUIT, 2012; Lévy, 1993). A partir da análise das respostas dos estudantes a um questionário e de dois vídeos produzidos na atividade, observamos que os principais obstáculos para a produção dos vídeos foram: vocabulário incipiente em Libras, a dificuldade em executar as expressões não-manuais e a falta de destreza com a edição dos vídeos. Em conclusão, apontamos que a atividade de produção de vídeos em Libras pode contribuir para uma melhora da prática de sinalização na língua, visto que os alunos são levados a pesquisar previamente os sinais que serão usados para a produção, trabalhando a autorregulação da aprendizagem.

Palavras-chave: Vídeo. Libras. Aprendizagem. Avaliação. Autorregulação.

\section{ABSTRACT}

This paper reports the analysis of a series of didactic activities involving the video production in Brazilian Sign Language (Libras) by students of this language in teacher training degree at the Núcleo de Formação Docente do Centro Acadêmico do Agreste da Universidade Federal de Pernambuco. First, we show some aspects of the role that Libras plays in college education. Second, we explain about evaluation and self-regulation in the teaching-learning process (SILVA, 2007; PERRENOUD, 1999). Finally, in the theoretical basis, we talk about mobile learning (BOTTENTUIT, 2012; Lévy, 1993). Analyzing the students answers from a questionnaire and two videos produced by them, we observed that the main obstacles to produce the videos were: low vocabulary knowledge, difficulty in non-manual expressions execution and lack of editing videos abilities. In conclusion, we point that video production activities in Libras can contribute to improve the signing skills in that language, considering that the students need to do previous research of signs that will be used, working on self-regulation of learning.

Keywords: Video. Libras. Learning. Evaluation. Self-regulation. 


\section{INTRODUÇÃO}

As línguas de sinais, assim como outras línguas, permitem criar poesias, contar estórias, fazer teatro, bem como discorrer sobre diversos assuntos como filosofia, política, literatura, esportes, trabalho, moda, educação, etc. Pesquisas como a de Quadros e Karnopp (2004) indicam que em comparação às línguas orais, as línguas de sinais têm o mesmo grau de complexidade e expressividade. "[...] as investigações mostram que as línguas de sinais, sob o ponto de vista linguístico, são completas, complexas e possuem uma abstrata estruturação em todos os níveis de análise" (QUADROS e KARNOPP, 2004, p.37).

A língua de sinais utilizada pela comunidade surda brasileira, a Libras, ganhou reconhecimento a partir da criação da Lei n 10.436 de 24 de abril de 2002 (BRASIL, 2002), que foi regulamentada pelo decreto 5.626 de 22 de dezembro de 2005 (BRASIL, 2005). Esse ato proporcionou, dentre outras coisas, a abertura do curso de Letras Libras para a formação de professores, preferencialmente surdos, para o ensino dessa língua. Outro ponto observado a partir dos pressupostos da lei foi a abertura de concursos públicos para que professores formados em Letras Libras lecionem a disciplina de Libras no nível superior, o que leva aos estudantes de cursos de licenciaturas diversas o acesso à essa língua, mesmo que de maneira básica, pois essa também é uma exigência da lei. Com isso, a Língua Brasileira de Sinais vem ganhando espaço nas universidades do Brasil, contribuindo para melhorias no contexto do seu ensino-aprendizagem, bem como no campo da pesquisa científica.

Os estudantes dos cursos de licenciaturas diversas são, em sua grande maioria, ouvintes que não tem a Libras como língua materna, o que a coloca em uma posição de segunda língua. A carga horária da disciplina de introdução à Libras é limitada a 30, 60, 90 ou 120 horas, no máximo, dependendo do Projeto Pedagógico do Curso, da oferta de disciplinas eletivas de Libras e do interesse dos alunos. Dentro desse cenário, pensamos em uma metodologia a partir da produção e avaliação de vídeos em língua de sinais que venha a contribuir para a motivação e qualidade da aprendizagem da Libras. 
$\mathrm{Na}$ educação superior, a aprendizagem dos alunos não depende apenas da presença do professor, mas também da procura por recursos e materiais didáticos diversos como, por exemplo, os recursos tecnológicos definidos dentro das Tecnologias da Informação e Comunicação para a Educação (TICs). Diversos autores afirmam que, com o desenvolvimento da tecnologia, é preciso haver mudanças radicais nos indivíduos, para que eles se adaptem à nova realidade da sociedade. (SMITH, 1992; GODOY, 1995; VALLANCE, 1995; OECD, 2000; ARMITAGE, 2002).

De acordo com Reyna (1997), com o uso do vídeo há um exame aprofundado do processo de ensino-aprendizagem analisado, pois o estudante tem a oportunidade de se autoavaliar, uma vez que depois de produzir o vídeo - filmar a si próprio sinalizando - ele deve assisti-lo para decidir se é preciso corrigir algum erro ou se ficou de acordo com o que foi solicitado pelo professor.

Com o desenvolvimento da tecnologia, o ensino presencial vem se modificando e dando lugar a formas de ensino com atividades virtuais. Hoje, podemos aliar duas formas de ensino: a presencial com aulas regulares, em que é possível uma relação direta e instantânea entre professor e estudante; e a virtual, através da produção e postagem de vídeos por parte dos estudantes nas mídias sociais, como Facebook, Blogs e plataformas institucionais. Assim, por meio da observação e filmagem, o educando passa a manifestar seus comportamentos, suas habilidades e a aprender de forma interativa (ABRAMOWICS, 1990).

De acordo com nossos levantamentos bibliográficos, por se tratar de algo novo, a produção de vídeos no processo de ensino-aprendizagem da Libras como segunda língua por futuros professores, é um fenômeno necessário de ser investigado.

Assim, o objetivo desta pesquisa foi investigar como uma atividade didática de produção de vídeos usando a Libras pode contribuir para a aprendizagem dessa língua por parte de alunos ouvintes de cursos de licenciaturas diversas. Buscamos compreender se o vídeo, desde a sua elaboração, produção e postagem, amplia as possibilidades de aprendizado da Libras e pode constituir um instrumento de avaliação 
da aprendizagem, além da importância de mantermos registros em vídeos acerca dessa língua dada à sua modalidade vísuo-espacial.

\section{REGISTRO DA LIBRAS}

As discussões acerca de uma forma de registro das línguas de sinais são consideradas recentes no Brasil e no mundo. Atualmente, se tem aprofundado nas pesquisas acerca do SignWriting, um sistema criado por Valerie Sutton em 1974. Sutton criou um sistema para transcrever movimentos de danças, o que despertou a curiosidade de pesquisadores da língua de sinais dinamarquesa que estavam à procura de uma forma de escrever os sinais. Hoje, estima-se que mais de 36 países utilizem essa forma de escrita de sinais em universidades, escolas e espaços públicos.

Contudo, por muito tempo a única forma de registro da língua de sinais foi o vídeo, passando inclusive pela película e pelo $\mathrm{VHC}$, sendo este último marcado por um período de grande produção de registros em língua brasileira de sinais. Ademais, o SignWriting ainda se encontra muito restrito às pesquisas e espaços acadêmicos, o que faz com que a gravação em vídeo seja, ainda, muito importante para o registro das línguas de sinais.

Assim, o registro em vídeo se torna mais do que necessário em sala de aula, considerando, também, os tempos atuais, em que os recursos tecnológicos, principalmente os aparelhos móveis como câmeras, celulares, tabletes, entre outros, possibilitam uma forma fácil e rápida de eternizar a fala dos indivíduos usuários das línguas de sinais.

Além de contribuir para o aprendizado dos discentes, sua avaliação e registro de memória particular, a utilização do vídeo como recurso pedagógico contribui significativamente como um registro histórico da língua de sinais em nosso país, reverberando no avanço dos estudos e das pesquisas em áreas como Linguística e Educação. 
Os professores têm como papel fundamental a preocupação com a melhoria e a qualidade do ensino, e a aprendizagem dos estudantes. Com a disciplina de Libras não é diferente. O professor de língua de sinais deve estar atento aos avanços e às novidades correspondentes ao seu componente curricular, pois

Percebemos que cada vez mais é preciso pesquisar na teoria a solução para os problemas da prática, no dia-dia em sala de aula. Buscamos na aprendizagem da Língua Brasileira de Sinais alternativas de novas técnicas e métodos diferenciados com o intuito de desenvolver um trabalho com maior qualidade. (COUTO E RUBIO, 2014, p. 18).

Portanto, é recomendável ao professor de língua de sinais estar atento às mudanças atuais e se adequar às novas formas e linguagens alternativas disponíveis, como a utilização do vídeo como componente avaliativo dentro da disciplina de Libras. A nossa proposta é que a produção de vídeo não se limite necessariamente ao final da disciplina, visto que ela pode estar presente em todas as etapas do início ao fim do semestre, entendendo a necessidade da avaliação contínua dos alunos pelo professor e da necessidade dos alunos também desenvolverem competências para se autoavaliarem.

\section{REFLEXÕES SOBRE AVALIAÇÃO E AUTORREGULAÇÃO}

Pensamos que a utilização de recursos audiovisuais no contexto de ensinoaprendizagem da Libras, pode funcionar como mecanismo de avaliação mediado pela autorregulação. Segundo Vasconcelos (2005), a avaliação deve ser um procedimento constante durante o processo de ensino-aprendizagem. A nota ou conceito é uma burocracia do sistema educacional ou da academia. Contudo, o professor deve ter em mente que a avaliação se configura como uma reflexão sobre a sua prática, para que, a partir dos resultados obtidos, observe a necessidade de mudar sua metodologia ou mantê-la. 
Por outro lado, avaliar não pode ser considerado um ato neutro, isolado e fora de contexto. De acordo com Silva (2007), a avaliação é estritamente política e pode estar a serviço de um modelo liberal, por consequência excludente, ou não liberal no qual o Estado assume uma postura de responsabilidade perante os cidadãos e busca incluí-los.

A autorregulação é um mecanismo que permite a professores e alunos se autoanalisarem. Perrenoud (1999, p. 96) explica que autorregulação significa "capacidades do sujeito para gerir ele próprio seus projetos, seus progressos, suas estratégias diante das tarefas e obstáculos". A transmissão do conhecimento feita pelo professor não pode ocorrer de maneira homogênea, pois em uma sala de aula são reunidos estudantes com pensamentos e conhecimentos de mundo diferentes uns dos outros, que compartilham opiniões e experiências também distintas. É quase inviável ao professor conseguir atingir a todos em suas singularidades. Assim, segundo Perrenoud (1999, p. 96):

\begin{abstract}
Para aprender, o indivíduo não deixa de operar regulações intelectuais. $\mathrm{Na}$ mente humana, toda regulação em última instância, só pode ser uma autoregulação [sic], pelo menos se admitirmos as teses básicas do construtivismo: nenhuma intervenção externa age se não for percebida, interpretada, assimilada por um sujeito. Nessa perspectiva, toda ação educativa só pode estimular o auto-desenvolvimento [sic], a autoaprendizagem [sic], a auto-regulação [sic] de um sujeito, modificando seu meio, entrando em interação com ele. Não se pode apostar, afinal de contas, senão na auto-regulação [sic].
\end{abstract}

Em determinados momentos da aula é possível perceber que a compreensão dos alunos sobre o conteúdo não foi a esperada pelo professor. Em situações como essas, o professor pode buscar outras formas de se expressar para transmitir o conteúdo, pois essas atitudes fazem parte do processo de autorregulação.

Também pensamos que os estudantes devem ser incentivados a autoprodução do conhecimento, em que podem adquirir e modificar as informações obtidas e elaborar novos conhecimentos. De acordo com Simão (2002, p. 13) “[...] reconhece- 
se a incapacidade de o homem consumir toda a informação, sendo, por conseguinte indispensável desenvolver o indivíduo como um ser estratégico, gestor da multiplicidade de dados com que tem que lidar". Assim, através da autorregulação, os estudantes podem avaliar a si mesmos, constituindo-se como sujeitos ativos e críticos na produção do conhecimento.

\title{
3 APRENDIZAGEM MÓVEL NO PROCESSO DE ENSINO-APRENDIZAGEM
}

Com a popularização da tecnologia, outro tipo de aprendizagem aparece como um recurso que auxilia o professor e atrai os estudantes da "geração tecnológica", denominada sociologicamente de geração $Z$, que seria a aprendizagem móvel, segundo Bottentuit (2012, p. 130):

\begin{abstract}
Mobile learning (M-learning), aprendizagem móvel ou aprendizagem com mobilidade é um conceito criado para a aprendizagem que utiliza recursos móveis, ou seja, equipamentos e dispositivos que permitam ao aprendiz a locomoção enquanto acessam o conteúdo, a este nível se enquadram dispositivos como: os celulares smartphones, notebooks, netbooks, palmtops, tablet pc, personal digital assitent (PDA), pocketpc etc.
\end{abstract}

A aprendizagem móvel se utiliza de recursos tecnológicos comuns aos estudantes que têm contato diário com recursos comunicacionais tecnológicos portáteis inseridos em seu cotidiano. Desta forma, a aprendizagem móvel se alia a educação regular, utilizando as mesmas ferramentas com a qual os discentes entram em contato com a sua realidade, com o seu mundo e suas vivencias prévias.

As pessoas com maior afinidade e facilidade em utilizar recursos tecnológicos podem aprender melhor através de atividades didáticas que se utilizem destas tecnologias. De acordo com Lévy (1993), é importante o uso de tecnologias digitais na educação, pois o aluno se envolve no processo didático e consegue adquirir de forma mais eficaz o conhecimento mediante uma pedagogia ativa. 
Com a utilização da aprendizagem móvel os discentes podem ter acesso rápido à grande diversidade de informação disponível na internet e em outras fontes de dados digitais, podem usar softwares educacionais específicos das múltiplas áreas do conhecimento, assim como uma grande variedade de produtos educacionais disponíveis on-line e off-line.

No universo do ensino, materiais audiovisuais são comumente utilizados pelos professores mediante apresentação de filmes, documentários e videoaulas. Em nosso trabalho, apostamos em uma metodologia em que os próprios alunos produzem vídeos didáticos ${ }^{1}$, pois pensamos que assim podemos aliar os benefícios das tecnologias com os processos de autoavaliação e autorregulação.

Pensamos que, através da atividade de produção de vídeos, os estudantes praticam o aprendizado concomitantemente ao que absorvem em relação à teoria durante as aulas. Além disso, na ementa desta disciplina específica, não havia a exigência da escrita de sinais, por isto a produção do vídeo se configurou como um registro de memória que pode ser acessado posteriormente sempre que se fizer necessário.

A atividade em vídeo também pode ser realizada dentro ou fora de sala de aula, seja de forma individual ou em grupo, pois pode haver uma ótima forma de trabalhar na zona de desenvolvimento proximal que se refere:

A diferença entre o que o aprendiz pode fazer individualmente e aquilo que é capaz de fazer com a ajuda de pessoas mais experimentadas, como outros aprendizes "especialistas" na matéria, ou o instrutor, esta formulação de Vygotsky reforça, simultaneamente, a importância do princípio de prontidão, que implica a necessidade do aprendiz ter alcançado um determinado estado de aptidão para apreender determinado material cognitivo (FINO, 2001, p. 06).

\footnotetext{
${ }^{1}$ Denominamos de vídeos didáticos os vídeos produzidos pelos alunos nas aulas de Libras como parte do processo de ensino-aprendizagem. Entendemos que os vídeos são recursos didáticos que contribuem para o aperfeiçoamento do processo de ensino-aprendizagem da Libras como uma língua visual e espacial.
} 
Ou seja, os discentes podem auxiliar uns aos outros durante a realização da atividade. Com isso, é possível trabalhar tanto a interação entre os estudantes, quanto sua autonomia, além do professor também atuar como um agente ativo no processo de aprendizagem do estudante.

\section{METODOLOGIA}

O presente trabalho tem como objetivo a análise da produção de dois vídeos, com 1 (um) minuto de duração cada, por estudantes da disciplina de Introdução à Libras, do Núcleo de Formação Docente do Centro Acadêmico do Agreste da Universidade Federal de Pernambuco. Nos vídeos, que foram postados no Facebook, os alunos utilizaram o vocabulário trabalhado nas aulas. Além desse material, também foram analisadas as respostas dos alunos a um questionário que lhes foi entregue após a produção dos vídeos.

Devido à natureza do problema em estudo e às questões e objetivos desta pesquisa, a mesma está pautada pelos princípios das abordagens: qualitativa e quantitativa. Embora haja diferenças significativas entre essas duas abordagens, alguns autores, vêm demonstrando a eficácia de uni-las, tendo em vista os benefícios de ambas na análise dos dados. Nessa perspectiva, Demo (1995, p.231) enfatiza que "embora metodologias alternativas facilmente se unilateralizem na qualidade política, destruindo-a em consequência, é importante lembrar que uma não é maior, nem melhor que a outra. Ambas são da mesma importância metodológica”.

Os participantes voluntários da pesquisa, os quais denominaremos estudantes participantes, responderam a um questionário ao final do processo de produção do vídeo como parte da coleta de dados. Obtivemos um total de 17 (dezessete) participações, sendo 09 (nove) do sexo feminino e 08 (oito) do sexo masculino, com idades entre 18 (dezoito) e 25 (vinte e cinco) anos. Os estudantes participantes eram, em sua totalidade, graduandos dos cursos de Licenciatura, matriculados na disciplina 
de Introdução á Libras, no período noturno. Na coleta e análise dos dados, os participantes voluntários foram identificados com a letra " $A$ " seguida de um número cardinal de 01 (um) a 17 (dezessete).

Seguimos as propostas de Gil (1999; 2008), Marconi e Lakatos (2003) e Gomes (2015) para a coleta de dados que foi realizada por meio da técnica de questionário, o qual será apresentado mais adiante. Segundo Gil (2008), o questionário é utilizado em sondagem ou inquérito e auxilia na coleta de informações, sejam elas ideias, crenças, opiniões, pensamentos, conhecimentos, valores que poderão servir para indicar o caminho para desvendar o objeto de investigação.

Responderam ao questionário os estudantes que aceitaram as condições da pesquisa e assinaram ao Termo de Consentimento Livre e Esclarecido (TCLE). Esse mesmo grupo de estudantes autorizou a utilização dos vídeos produzidos na disciplina para coleta de dados desta pesquisa

No primeiro vídeo, foi solicitado aos estudantes que fizessem uma apresentação pessoal, dizendo o seu nome e em seguida alguns cumprimentos e saudações em Libras. No segundo vídeo lhes foi solicitado que apresentassem duas frases em Libras.

Para análise dos resultados, com relação à aprendizagem da Libras e ao uso adequado dos sinais nos vídeos, usamos como referência os parâmetros das línguas de sinais que, de acordo com a definição de Quadros \& Karnopp (2004) são: a configuração de mão, o ponto de articulação, o movimento, a orientação e as expressões não-manuais, estas últimas também conhecidas como expressões faciais e corporais.

O questionário foi elaborado como instrumento de coleta de dados para complementar a investigação e elaborar os resultados, conclusões e perspectivas. Ele foi organizado através de perguntas abertas, permitindo que os conteúdos das respostas se tornassem mais evidentes do que ocorre com um questionário composto por perguntas fechadas, que são mais diretivas (LIBERALI;LIBERALI, 2011). O questionário foi composto pelas seguintes perguntas: 
1. Quantos vídeos você produziu e postou no Facebook durante a disciplina?

2. O que você utilizou para gravar o vídeo?

3. Você gravou o vídeo sozinho ou teve ajuda de alguém?

4. Antes de gravar o vídeo você utilizou algo parecido com um roteiro? Pesquisou sobre os sinais? Como?

5. Você ensaiou antes de gravar o vídeo? Quantas vezes? Gravou várias vezes para escolher o vídeo?

6. Sentiu vergonha ou constrangimento para gravar o vídeo? Explique.

7. Você se sentiu estimulado ou motivado ao fazer o vídeo? Explique.

8. Você acha que todo o processo de produção dos vídeos contribuiu para aprender mais a Libras?

Por meio de Liberali e Liberali (2011), utilizamos método quantitativo na análise dos vídeos a fim de verificarmos em termos numéricos como se deu a execução dos parâmetros fonológicos da Libras pelos estudantes, mediante a classificação de "ótimo", "bom", "regular", "insuficiente" e "ausente".

Ainda a partir de Liberali e Liberali (Idem) e Gil (2008), empregamos a análise qualitativa na execução dos parâmetros fonológicos, buscando elencar as possíveis causas para os diferentes níveis de execução desses parâmetros; e nos questionários, em que nos debruçamos sobre as percepções dos estudantes participantes sobre a produção dos vídeos didáticos.

Mediante o que foi apresentado na metodologia, partiremos para a análise dos dados e discussão dos resultados. 


\section{RESULTADOS E DISCUSSÃO}

Nesta etapa da pesquisa analisaremos as respostas dos questionários e depois os vídeos produzidos. Como esperado, quase todos os alunos usaram o celular com câmera para gravar os vídeos; apenas 1 (um) usou o Ipad. Embora acreditemos que outros dispositivos, como câmeras fotográficas e filmadoras, são mais adequados para a produção desse tipo de material, por apresentar maior qualidade e resolução, sabemos que os estudantes estão mais familiarizados com o celular, que contém diversas funcionalidades e aplicativos para a produção, edição e upload dos vídeos nas redes sociais.

Com relação à pergunta de número 3 do questionário sobre o auxílio para realização da atividade, identificamos que 11 (onze) estudantes interpelados necessitaram de ajuda, 5 (cinco) iniciaram sozinhos e depois precisaram de algum tipo de ajuda e 1 (um) gravou sozinho sem precisar de nenhum tipo de ajuda. $O$ fato de que a grande maioria precisou de ajuda para realizar o trabalho, nos faz refletir sobre questões relacionadas às formas como os alunos trabalham e desenvolvem estratégias de aprendizagem.

Em princípio, somos levados a pensar que os estudantes têm poucas habilidades com todo o processo de gravação, edição de vídeos e a posterior postagem nas redes sociais porque não é comum este tipo de atividades didáticas no ensino fundamental e médio, nem no ensino superior.

Sabemos que grande parte dos estudantes prefere realizar trabalhos de forma cooperativa, pois existem relações solidárias nos grupos sociais que se configuram dentro de uma sala de aula. Essas relações se fortalecem e se diversificam ao longo do curso. Estudar e aprender de forma cooperativa e solidária humaniza o ensino, assim como permite que se desenvolvam outras formas de aprendizagem além da individual, pois de forma coletiva os alunos desenvolvem formas de comunicação diferentes da comunicação professor-aluno. Podemos dizer que a comunicação aluno-aluno é mais descontraída e livre, o que permite que possam intercambiar dúvidas e compreensões mutuamente. 
As razões pelas quais os alunos têm esse tipo de relação pode ser justificada pela falta de habilidade leva os alunos a procurar ajuda dos colegas mais próximos ou dos mais habilidosos, o que faz com que se estabeleçam relações solidárias e cooperativas, gerando outras formas de ensino-aprendizagem.

Autores como Ellis (1997), Karabenick \& Sharma (1994), Newman (1994, 1998) e Zimmerman \& Martinez-Pons (1988) discorrem sobre a tática de pedir ajuda como estratégia de aprendizagem. Durante a atividade didática acontece um processo de autoavaliação que leva o aluno a saber se precisa ou não de ajuda. Neste sentido, Newman (1998) afirma que pedir ajuda pode estimular uma atividade metacognitiva pela sua natureza reflexiva, porque os estudantes desenvolvem a aprendizagem a partir de suas próprias estratégias mentais. Assim, pedir ajuda acadêmica necessariamente abarca outras pessoas com as quais o estudante terá que interagir e de quem possivelmente receberá assistência.

Neste sentido, se o aluno fizer sozinho determinada atividade, pode sentir-se inseguro em relação à adequação ou não do seu trabalho aos critérios avaliativos do professor e sente a necessidade do acompanhamento de outros alunos, assim, pedir ajuda é uma boa estratégia para a obtenção de melhores resultados. Isso coaduna com o que havíamos discorrido acerca da zona de desenvolvimento proximal, pois é através da oportunidade de colocar em prática sua criatividade, por meio de atividades como a produção de vídeos, que os alunos podem, de forma coletiva, encontrar possibilidades para a criação de novos significados.

A partir da análise das respostas à pergunta 5 , sobre ensaio e repetição para a produção dos vídeos, identificamos que 11 (onze) estudantes gravaram várias vezes, ou seja, com ensaio, enquanto 6 (seis) fizeram sem ensaiar. Entendemos que essa repetição é consequência da autoavaliação durante o processo da produção do vídeo, contribuindo para que o estudante execute a atividade até ficar satisfeito com o resultado. Como aponta Alves (2007), a repetição não pode ser um fim em si mesma, mas um meio pelo qual o estudante atinge o conhecimento após estabelecer relação com o conteúdo. 
O estudante deve atingir os objetivos propostos pelo docente, mas também quer obter um produto com qualidade, não apenas cumprir com uma obrigação acadêmica. Todo esse processo de repetição, relacionada à reflexão do conteúdo estimula também a autorregulação.

Em relação a motivação durante a produção dos vídeos, obtivemos o resultado positivo com 17 (dezessete) estudantes que se declaram estimulados e motivados a produzirem vídeos, outros 03 (três) estudantes deixaram em branco.

Selecionamos algumas respostas dos estudantes que responderam positivamente a sétima questão do questionário, as respostas estão no quadro 1.

Quadro 1 - Sistematização de análise da sétima questão do questionário

\begin{tabular}{|c|l|}
\hline A2 & $\begin{array}{l}\text { Sim, pois estava em contato com uma comunidade surda e ouvinte e tinha a } \\
\text { oportunidade de aprender mais. }\end{array}$ \\
\hline A4 & Sim, pois as aulas me faziam ter vontade de pôr em prática o que aprendi. \\
\hline A6 & $\begin{array}{l}\text { Sim, além do estímulo, me senti desafiado a gravar os vídeos. De certa forma, } \\
\text { aumentou consideravelmente a vontade de aprender ainda mais sobre Libras. }\end{array}$ \\
\hline A8 & $\begin{array}{l}\text { Sim, pois foi através da prática, dos erros e das tentativas que a motivação em } \\
\text { concluir a atividade foi aumentando. }\end{array}$ \\
\hline A12 & Sim, por ser uma atividade diferente, dá muita vontade de fazer. \\
\hline A17 & Sim. Era desafiador e auto-avaliativo. Essas condições me estimulavam. \\
\hline
\end{tabular}

Fonte: arquivos produzidos pelos autores (2017)

Segundo o estudante (A2) a atividade em vídeo foi estimulante pelo contato com a comunidade surda e, conseguintemente, o fez aprender mais. Observamos que este tipo de atividade em formato de vídeo se configura como algo essencial, pois trabalha a prática e a percepção, fazendo com que o estudante compreenda o conteúdo proposto pelo componente curricular em questão. Como podemos observar 
na resposta do estudante (A4), o discente chama a atenção para a importância de se pôr em prática o que aprende nas aulas.

Além do mais, ao serem desafiados a produzirem vídeos, os estudantes relataram que se sentiram estimulados a aprender mais, como podemos observar nas falas dos discentes (A6) e (A17). Isso se dá porque os estudantes, ao se depararem com a produção de vídeo, se veem, também, na condição de pesquisadores, pois tiveram que buscar novos sinais da Libras e novos conhecimentos para adicionar ao seu material. Pensamos que este tipo de atividade teórico-prática contribui fortemente no processo formativo, pois de acordo com Moran (1995, p.17):

\begin{abstract}
Educar é ajudar a desenvolver todas as formas de comunicação, todas as linguagens: aprender a dizermos, a expressarmos claramente, a captar a comunicação do outro a interagir com ele. É aprender a comunicarmos verdadeiramente: a ir tornando-nos mais transparentes, expressando-nos com todo corpo, com a mente, com todas as linguagens, verbais e não verbais, com todas as tecnologias disponíveis.
\end{abstract}

Os estudantes relataram que a proposta de produzir algo os ajuda a aprender mais do que a simples explanação de conteúdos como nas aulas convencionais. Também observamos na fala de (A8) que os estudantes, ao produzirem seus vídeos, praticam o processo de autoavaliação. Isso está de acordo com Simão (2002) e Silva (2004) que retratam a necessidade do discente ter autonomia para gerir suas atividades e elaborar estratégias para a conclusão da mesma, além de se reconhecer como um ser humano que precisa se aprimorar, na tentativa de chegar a seus objetivos.

Continuando nossa análise dos dados, observamos que a utilização de recursos tecnológicos contribui para estimular mais o interesse dos discentes, como relata (A12). Ademais, o uso desses recursos aproxima a academia do cotidiano dos estudantes, fazendo com que eles se sintam aptos a executar a tarefa proposta.

Além disso, percebemos durante as aulas que alguns dos discentes matriculados na disciplina de Libras não tinham contato prévio com a comunidade surda, nem sequer notavam os surdos nos espaços públicos. Diante disso, a utilização 
dos recursos tecnológicos foi um fator relevante para estimular o interesse dos alunos pela Libras.

Após o término do semestre, os discentes relataram que passaram a perceber os surdos fora do ambiente da universidade. Isso demonstra que a disciplina de Libras contribuiu para dar visibilidade ao sujeito surdo perante a sociedade, visto que foi a partir da experiência com a disciplina de Libras na graduação que os surdos passaram a "existir" para os alguns dos discentes dessa turma.

Podemos afirmar que isso ocorre frequentemente em relação aos grupos sociais para os quais a inclusão social é uma necessidade, pois o resto da sociedade não os "enxerga" adequadamente enquanto as políticas públicas não são, de fato, implementadas.

Após análise da última pergunta "Você acha que todo o processo de produção dos vídeos contribuiu para aprender mais Libras?", uma das mais importantes desse trabalho, obtivemos os seguintes resultados:

- 13 (treze) estudantes responderam positivamente ao declararem que produzir vídeos contribuiu de forma significativa para o seu aprendizado;

- 03 (três) estudantes deixaram em branco;

- 01 (um) estudante respondeu negativamente, porém o complemento da sua resposta indica que a produção de vídeo auxiliou no aprendizado do conteúdo.

Abaixo, vemos as considerações dos participantes:

Quadro 2 - Sistematização de análise de questionário

\begin{tabular}{|c|l|}
\hline A1 & $\begin{array}{l}\text { Sim, pois no meio dos vídeos sempre surgia alguma dúvida e isso fazia eu aprender sinais } \\
\text { novas. }\end{array}$ \\
\hline A3 & Sim pois motivou os alunos a pesquisar novos sinais, estimulando o aprendizado. \\
\hline
\end{tabular}




\begin{tabular}{|c|l|}
\hline A6 & $\begin{array}{l}\text { Sim, pois ao ensaiar os sinais e gravar várias vezes acabou desenvolvendo uma fixação } \\
\text { dos sinais em meu vocabulário. Sem dúvida alguma, a produção dos vídeos só contribuiu } \\
\text { para a aprendizagem de Libras. }\end{array}$ \\
\hline A11 & $\begin{array}{l}\text { Com certeza. Gravar os vídeos faziam com que eu pesquisasse mais sinais e aprendesse } \\
\text { mais. }\end{array}$ \\
\hline A12 & $\begin{array}{l}\text { Não, pois focava em fazer o vídeo e os sinais só por aquele momento fazendo assim que } \\
\text { você aprendesse muito. }\end{array}$ \\
\hline A13 & $\begin{array}{l}\text { Sim, bastante. O vídeo propiciou entrar em situações diversas e poder aprender mais. Tive } \\
\text { que pesquisar, entender interpretar, aguçar o sentido visual e treinar. }\end{array}$ \\
\hline A16 & Sim, porque teríamos que aprender e ver sentido no que estávamos fazendo. \\
\hline
\end{tabular}

Fonte: arquivos produzidos pelos autores (2017)

Como podemos ver nas respostas de (A1) e (A3), a utilização do vídeo como recurso didático estimula o surgimento de dúvidas. Isso nos leva a perceber que os estudantes são movidos a questionar sua prática e a pesquisar em busca de respostas e soluções para os problemas que surgem durante a atividade. Assim, os alunos têm a oportunidade de refletir criticamente acerca de suas práticas.

Na resposta de (A6), percebemos que o uso do vídeo contribui para a melhor assimilação dos sinais propostos e, consequentemente, o aumento do vocabulário dos discentes. Isso ocorre porque os estudantes saem da zona de conforto de uma aula expositiva e vão para a prática, o que possibilita que eles percebam e apreendam os sinais em contextos de interação efetiva em sala de aula.

Além disso, os estudantes também são instigados a buscar outras fontes de conhecimento, promovendo maior aprendizado ao romperem os limites da sala de aula e ampliarem seu repertório linguístico de forma autônoma e consciente como podemos ver nas respostas de (A11) e (A12).

A partir da resposta do discente (A13), verificamos que a produção dos vídeos estimulou outras formas de perceber a utilização dos sentidos do campo visual. Em seu cotidiano, pessoas ouvintes estão acostumadas a utilizar a fala, através de estímulos auditivos, como principal meio de comunicação. 
Com essa atividade, o sentido relacionado à visão é aguçado, fazendo com que o discente se aproprie da Libras, que é uma língua de modalidade vísuo-espacial (QUADROS, 2004). Dessa forma, os alunos podem perceber a organização visual e espacial da Libras como um aspecto intrínseco dessa língua, dada à sua modalidade.

Vale ressaltar que o discente (A16) ainda demonstra, em sua resposta, a importância da autorregulação (PERRENOUD, 1999). Nesse sentido, vemos que a atividade forneceu subsídios aos alunos para que pudessem se analisar mediante as estratégias utilizadas por eles, gerando progressos.

Na etapa posterior, fizemos a análise dos vídeos, verificando a execução dos parâmetros fonológicos ${ }^{2}$ da Libras, como um aspecto constitutivo da organização gramatical dessa língua, pois tais parâmetros compõem a formação dos sinais no sistema fonológico da Libras. É, então, através desta análise que podemos apontar os possíveis erros na sinalização dos discentes.

No primeiro vídeo, solicitamos que os estudantes elaborassem uma apresentação pessoal contendo saudações (bom dia, boa tarde), nome e sinal. O vídeo deveria ter no máximo 1 (um) minuto de duração. A partir dessa pequena apresentação, podemos avaliar como os discentes estavam sinalizando o conteúdo dado até aquele instante. O quadro 3 apresenta a análise do primeiro vídeo dos 17 participantes.

Quadro 3 - Análise em conformidade com os parâmetros fonológicos da Libras no primeiro vídeo de cada participante

A1, A5, A6 A10, A11, A13 A14
Realizou a maioria dos parâmetros de forma satisfatória, porém faltou efetuar a expressão facial de forma mais forte, condizente com o sinal proposto.

\footnotetext{
2 De acordo com Quadros (2004), os parâmetros fonológicos da Libras são configuração de mão (CM), ponto de articulação (PA), movimento $(\mathrm{M})$, orientação da palma da mão $(\mathrm{O})$ e expressão facial e corporal (EF).
} 


\begin{tabular}{|c|l|}
\hline \multirow{2}{*}{ A2, A7, A9, A17 } & Utilizou a configuração de mão incorreta. \\
\cline { 2 - 2 } & $\begin{array}{l}\text { Faltou efetuar a expressão facial de forma mais forte, condizente com o sinal } \\
\text { proposto. }\end{array}$ \\
\hline \multirow{2}{*}{ A8 } & $\begin{array}{l}\text { Realizou a maioria dos parâmetros de forma satisfatória, mas utilizou o sinal com } \\
\text { movimento de forma exagerada. }\end{array}$ \\
\cline { 2 - 3 } & $\begin{array}{l}\text { Faltou efetuar a expressão facial de forma mais forte, condizente com o sinal } \\
\text { proposto. }\end{array}$ \\
\hline A12, A15 & $\begin{array}{l}\text { Realizou a maioria dos parâmetros de forma satisfatória, entretanto não utilizou } \\
\text { expressão facial e corporal. }\end{array}$ \\
\hline A3, A4, A16 & Não produziu o vídeo. \\
\hline
\end{tabular}

Fonte: arquivos produzidos pelos autores (2017)

Posteriormente, fizemos uma sistematização da análise do primeiro vídeo, a partir dos seguintes critérios:

- Ótimo: executou os parâmetros de forma correta.

- Bom: Apresenta pequenas falhas na execução.

- Regular: Apresenta falhas moderadas na execução.

- Insuficiente: Apresenta falhas na execução.

- Ausência: Não executou os parâmetros de forma correta.

Ordenamos os parâmetros considerando desde o parâmetro para o qual houve a maior quantidade de acertos até o que apresentou mais falhas na execução. Com isso, fica mais evidente o parâmetro para o qual o estudante apresentou mais dificuldade na hora de elaborar sua apresentação, possibilitando ao professor identificar estratégias para auxiliar o discente no aspecto que mais dificulta a execução do parâmetro fonológico. 
De acordo com Revista da Feneis (1999, 2002, p. 16), "na combinação destes quatro parâmetros, ou cinco, tem-se o sinal. Falar com as mãos é, portanto, combinar estes elementos que formam as palavras e estas formam as frases em um contexto". Diante disso, a falta de mais de um dos parâmetros pode confundir a comunicação, fazendo com que o discente fuja do contexto e atrapalhe seu processo de assimilação da gramática da Libras.

O gráfico abaixo mostra apenas o resultado com os 14 (catorze) estudantes que responderam, pois 3 (três) estudantes deixaram sua resposta em branco.

Gráfico 1 - Resultado da sistematização da análise da execução dos parâmetros fonológicos da Libras no primeiro vídeo

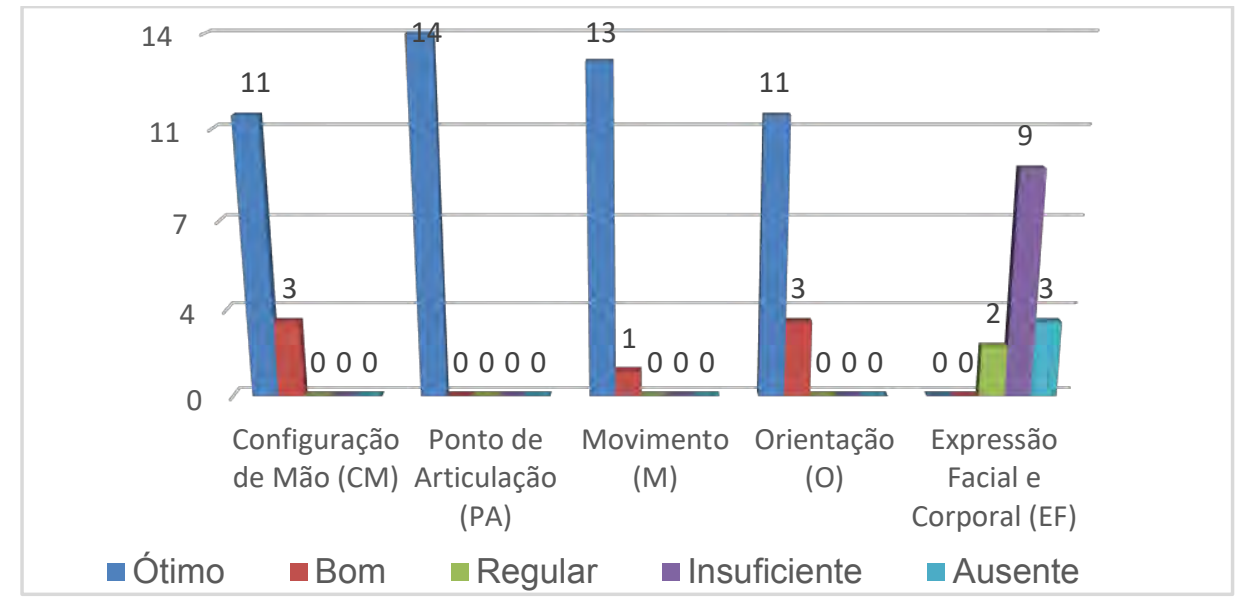

Fonte: arquivo produzidos pelos autores (2017)

Podemos observar claramente no gráfico 1 que o parâmetro que apresentou menos falhas foi parâmetro ponto de articulação (PA) e o que apresentou mais dificuldade foi o parâmetro expressão facial $(E F)$. Supomos que os discentes estavam mais preocupados em lembrar dos sinais no tocante à sua forma manual e, por isso, deixavam a expressão facial e corporal em segundo plano. 
Outra hipótese é que os falantes de línguas orais expressam suas emoções alterando o tom de voz, também deixando as expressões faciais em segundo plano, diferente dos usuários de línguas de sinais cuja expressão facial se configura como algo primordial a compreensão da mensagem, visto que é um aspecto estrutural da gramática das línguas de sinais.

No segundo vídeo, pedimos que os estudantes escolhessem duas frases que aprenderam no decorrer da disciplina de Libras e produzissem um vídeo de até 1 (um) minuto sinalizando as mesmas. Por meio dessa atividade, verificamos a autonomia dos discentes na escolha das frases, e avaliamos a sinalização apresentada no vídeo através da execução dos parâmetros fonológicos, conforme está posto no quadro 4.

Quadro 4 - Análise pormenorizada do segundo vídeo de cada participante.

\begin{tabular}{|c|c|}
\hline \multirow{3}{*}{ A1 } & $\begin{array}{l}\text { Realizou a maioria dos parâmetros de forma satisfatória, mas utilizou o ombro } \\
\text { como ponto de articulação, o correto seria no peito. }\end{array}$ \\
\hline & Realizou o sinal com o movimento errado. \\
\hline & Executou o sinal com configuração de mão incorreta. \\
\hline A2 & $\begin{array}{l}\text { Realizou a maioria dos parâmetros de forma satisfatória, entretanto executou o } \\
\text { sinal com o movimento errado. }\end{array}$ \\
\hline \multirow[t]{2}{*}{ A3, A4, A7 } & $\begin{array}{l}\text { Realizou a maioria dos parâmetros de forma satisfatória, entretanto executou o } \\
\text { sinal com o movimento incorreto. }\end{array}$ \\
\hline & Não utilizou nenhuma expressão facial corporal. \\
\hline \multirow[t]{2}{*}{ A8, A13, A14 } & $\begin{array}{l}\text { Realizou a maioria dos parâmetros de forma satisfatória, mas utilizou a } \\
\text { configuração de mão incorreta. }\end{array}$ \\
\hline & Não utilizou nenhuma expressão facial e corporal. \\
\hline $\begin{array}{c}\text { A5, A9, A10, } \\
\text { A11, A15, A16, } \\
\text { A17 }\end{array}$ & $\begin{array}{l}\text { Realizou a maioria dos parâmetros de forma satisfatória, entretanto falta aplicar } \\
\text { mais expressão facial e corporal a sua sinalização. }\end{array}$ \\
\hline $\mathrm{A} 6, \mathrm{~A} 12$ & Não produziu o vídeo. \\
\hline
\end{tabular}


No gráfico 2, apresentamos o resultado da sistematização da análise do uso dos parâmetros fonológicos neste segundo vídeo. O gráfico mostra apenas o resultado com os 15 (quinze) estudantes que responderam, pois 2 (dois) estudantes deixaram sua resposta em branco. 
Gráfico 2 - Resultado da sistematização da análise da execução dos

Parâmetros fonológicos da Libras no segundo vídeo

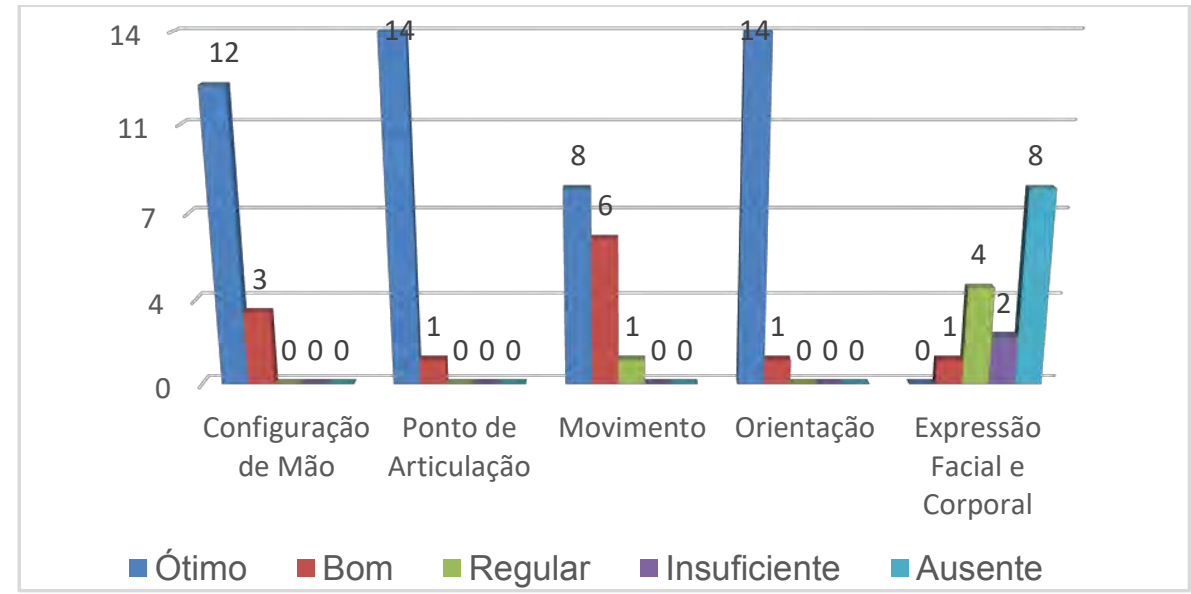

Fonte: arquivo produzido pelos autores (2017)

Observamos, novamente, que o parâmetro Ponto de Articulação e Expressão Facial e Corporal foram os que apresentaram mais acertos e mais falhas, respectivamente. Nessa perspectiva, pensamos que os próximos vídeos produzidos pelos estudantes podem apresentar resultado semelhante, com maiores problemas no mesmo parâmetro fonológico.

\section{CONSIDERAÇÕES FINAIS}

De acordo com o decreto 5.626 de 25 de dezembro de 2005 as disciplinas de Libras devem ser ofertadas para cursos de licenciatura e fonoaudiologia (BRASIL, 2005), porém não especifica a carga horária que deve ser ofertada. Não obstante, em algumas universidades, a carga horária obrigatória de Libras é de 60 horas, a qual pode não ser suficiente para o aprendizado dos estudantes, pois pensamos que não é viável aprender uma língua como a Libras, complexa como qualquer língua oral, em 60 (sessenta) horas. 
Tendo isso em vista, a atividade em vídeo, por estar atrelando teoria e prática, pode acelerar um pouco mais o processo de aprendizagem do estudante. Além de ser algo atrativo e estimulante, porque traz o uso da tecnologia, presente no cotidiano, para a prática acadêmica, e possibilita a construção do conhecimento de forma coletiva e criativa por meio da zona de desenvolvimento proximal ao trabalhar a interação e a autonomia dos estudantes.

Para endossar as conclusões e perspectivas deste trabalho procuramos, no processo de análise dos vídeos e das respostas dos questionários, identificar possíveis fatores limitantes para a elaboração dos vídeos, assim como contribuições do processo de elaboração do vídeo para a aprendizagem da Libras e, finalmente, estabelecer parâmetros de avaliação da aprendizagem de Libras por meio dos vídeos.

Em relação às possíveis limitações para elaboração dos vídeos, identificamos que os 17 (dezessete) participantes da pesquisa tiveram alguns empecilhos durante as filmagens. $\mathrm{O}$ vocabulário reduzido em Libras por parte dos discentes e a falta de destreza com a edição do vídeo, foram os principais obstáculos para os estudantes. Além dessas limitações mais recorrentes, o constrangimento de estar sendo filmado também foi relatado pelos estudantes. Porém, eles declararam que, no decorrer da disciplina, tal constrangimento diminuiu, levando-os à superação da insegurança.

Verificamos que no processo de preparação para gravar o vídeo, podem aparecer sinais que o estudante não conhece. Então, ele se sente estimulado a pesquisar os novos sinais, recorrendo a tecnologias como aplicativos de celular ou sites de internet, contribuindo para a ampliação do seu vocabulário de sinais na Libras.

Além disso, é possível refazer as gravações quantas vezes forem necessárias para que a execução seja de forma adequada. Dessa forma, o vídeo funciona como um registro, um espaço de memória no qual o estudante pode acessar sempre que se fizer necessário para relembrar a sinalização, um sinal específico, ou um dos parâmetros fonológicos que ele tenha vontade de aprimorar.

Nesse sentido, o vídeo funciona como uma "escrita" dos sinais que foram trabalhados na disciplina, pois o vídeo pode ser a forma mais palpável de anotação 
nesse momento de contato inicial dos estudantes com a Libras ao permitir, através do auxílio do professor, retomar a atividade e fazer ajustes e observações acerca da sinalização executada no vídeo.

Durante a análise dos vídeos, identificamos algumas dificuldades na execução da atividade, porém tais dificuldades podem ser facilmente contornadas, porque os alunos apresentam atração pelos recursos tecnológicos. Segundo Bottentuit Junior e Coutinho (2007, p. 614) "o estudante chega à escola hoje com conhecimentos tecnológicos já adquiridos e cabe à escola aprofundar estes saberes e consolidar novas práticas".

Assim, os estudantes que constroem uma experiência social com a tecnologia têm facilidade de se desenvolver, buscam aperfeiçoar suas técnicas e ainda aprendem novos conhecimentos que podem aplicar às tecnologias que eles já dispõem ou têm acesso com facilidade.

Também constatamos que é preciso descobrir novas estratégias e encontrar e/ou elaborar novos materiais para estimular a aquisição das Expressões Faciais. Por hora, elas podem ser percebidas com a observação de histórias infantis contadas em vídeo e, em seguida, pode-se fazer uso do celular, no qual o estudante pode se filmar e posteriormente observar suas expressões, ou utilizar um simples espelho para se autoanalisar e praticar os sinais junto com as expressões faciais.

Quadros (2004) aponta para a importância fundamental das expressões nãomanuais, pois fazem parte da estrutura da Libras e auxiliam no entendimento do contexto em que os sinais estão sendo executados, sendo esse parâmetro fonológico primordial para marcar sentenças interrogativas, relativas, concordância, foco, dentre outros aspectos.

Diante disso, sugerimos atualizar as ementas da disciplina de Libras no ensino superior, a fim de dar maior ênfase ao ensino das expressões não manuais. Dessa forma, o professor poderá planejar a aula trazendo novos autores e utilizando um tempo maior à prática dessas expressões, mediante a proposição de atividades em que os estudantes se observem e estimulem uns aos outros a corrigir suas 
expressões. Porém, a efetivação dessas mudanças exige estudos mais aprofundados no campo do ensino de língua brasileira de sinais.

Através da intersecção da tecnologia e do conteúdo, percebemos que o vídeo estimula os alunos à pesquisa, à autoavaliação e à autorregulação, além de contribuir para absorção do conteúdo proposto.

A utilização do celular como ferramenta móvel foi escolhida por ser um acessório utilizado pela massiva maioria dos estudantes. Além de não ser necessários outros recursos para implementar o celular como instrumento pedagógico, a tecnologia audiovisual se encaixou perfeitamente à disciplina de Libras por se tratar de uma língua vísuo-espacial, ou seja, de uma língua que utiliza o sentido da visão como canal para estabelecer comunicação.

Portanto, o celular utilizado como recurso pedagógico possibilitou a interação dos educandos com o mundo visual da Libras, além de os conectar com o seu cotidiano, uma vez que a maioria dos educandos faz uso diário do celular.

O celular possibilitou aos estudantes uma aprendizagem móvel, visto que eles puderam registrar suas atividades em diferentes espaços e momentos. Destacamos que este tipo de atividade constitui, de fato, um instrumento de avaliação, pois durante a produção, os estudantes foram levados a pesquisar e revisar previamente os sinais solicitados. Com isso, trabalhamos a autonomia dos discentes que encontraram suas próprias estratégias para a confecção do vídeo.

A gravação se torna fundamental para que o estudante se observe posteriormente e se autorregule, podendo perceber seus acertos e erros para uma possível correção da sinalização e enriquecer a linguagem com novas expressões. A realização de dois vídeos em sequência possibilitou que os estudantes notassem sua própria evolução na sinalização em Libras, o que os estimulou, segundo relatos dos próprios estudantes, a querer buscar mais conhecimento sobre o assunto.

Constatamos que o vídeo estimula a interação e a superação da timidez como observou Martiani (1998). Portanto, a produção de vídeos pode ser uma poderosa 
ferramenta para o ensino e para a aprendizagem, atraindo, principalmente, o público mais jovem que faz uso do celular quase diariamente.

Por outro lado, a utilização do vídeo como recurso pedagógico dentro da disciplina de Libras pode contribuir para o aprimoramento dos conteúdos e metodologias de ensino da própria disciplina, porque é por meio do registro do vídeo em Libras que novas pesquisas podem ser elaboradas com intuito de investigar como se desenvolve o ensino de Libras no espaço acadêmico e quais são as principais atualizações e reformas a serem feitas no tocante à disciplina. Ademais, esse registro contribui para a própria língua em questão, uma vez que, por ter uma escrita ainda pouco difundida, a Libras obteve poucos registros materiais ao logo de sua história.

Esta pesquisa se identifica mais com o tipo de avaliação formativa reguladora, porque buscamos um método que permitisse uma avaliação contínua e permanente, que possibilitasse tanto ao docente quanto ao educando refletir sobre sua prática de ensino e aprendizagem e adequá-la às situações reais. Consequentemente, o processo se torna mais flexível e dinâmico, o que permite modificações pontuais que auxiliam na adaptação da disciplina de acordo com as necessidades da turma.

Finalmente, pensamos que seriam necessários projetos de pesquisa e extensão que enfatizassem estudos no campo das expressões não manuais em Libras. Esses projetos poderiam estimular o crescimento e o fortalecimento das pesquisas em língua de sinais nos espaços acadêmicos, além de envolver alunos e docentes de forma interdisciplinar, agregando outras áreas ao universo da Libras.

\section{REFERÊNCIAS}

ABRAMOWICZ, M. Avaliação da aprendizagem: como trabalhador e estudantes de uma faculdade particular noturna veem o processo - em busca de um caminho. Tese (Doutorado em Educação). São Paulo: Pontifícia Universidade Católica de São Paulo; 1990.

ALVES, M. F. Da repetição para a aprendizagem: desenvolvimento cognitivo por meio da interação. Veredas. Minas Gerais. 2007 
BOTTENTUIT JUNIOR, João Batista; COUTINHO, Clara Pereira. Podcast em Educação: um contributo para o estado da arte. In: IX Congresso Internacional Galego Português de Psicopedagogia, 2007, A Coruña. Revista Galego-Portuguesa de Psicoloxía e Educación. A Coruña: Barca, A., Peralbo, M., Porto, A., Duarte da Silva, B. e Almeida, I. (Eds.), 2007. v. 1. p. $837-846$.

BOTTENTUIT JUNIOR, J. B. Do Computador ao Tablet: Vantagens Pedagógicas na Utilização de Dispositivos Móveis na Educação. Revista EducaOnline, Rio de Janeiro, 2012

BRASIL. Lei $\mathbf{n}^{0} \mathbf{1 0 . 4 3 6}$ de 24 de abril de 2002. Dispõe sobre a Língua Brasileira de Sinais Libras e dá outras providências. Diário Oficial, Brasília, DF, 25 abr. 2002. Disponível em: http://www.planalto.gov.br/ccivil_03/leis/2002/l10436.htm. Acesso em: 16 abr. 2018.

BRASIL. Decreto $n^{\circ} 5.626$ de 22 de dezembro de 2005. Regulamenta a Lei no 10.436, de 24 de abril de 2002, que dispõe sobre a Língua Brasileira de Sinais - Libras, e o art. 18 da Lei no 10.098, de 19 de dezembro de 2000. Diário Oficial, Brasília, DF, 23 dez. 2005. Disponível em: http://www.planalto.gov.br/ccivil_03/_ato2004-2006/2005/decreto/d5626.htm. Acesso em: 16 abr. 2018.

COUTO, L. F., RUBIO, J. A. S., Libras: uma análise histórica na perspectiva da educação inclusiva. Revista Eletrônica Saberes da Educação - Volume 5 - nº 1 - 2014

DEMO, P. Metodologia Científica em Ciências Sociais. São Paulo: Atlas, 1995.

FINO, C. N. Vygotsky e a Zonda de Desenvolvimento Proximal (ZDP): três implicações pedagógicas. in Revista Portuguesa de Educação, vol 14 n² 2, pp. 273-291, 2001.

GIL, Antonio Carlos. Como elaborar projetos de pesquisa. 4. ed. São Paulo: Atlas, 2008.

LÉVY, P. As tecnologias da inteligência: o futuro do pensamento na era da informática. Rio de Janeiro: Editora 34, 1993.

LIBERALI, Fernanda; LIBERALI, André Ricardo. Para pensar a metodologia de pesquisa nas ciências humanas. In: Faculdades Integradas Coração de Jesus. Rede Salesianas de Ensino - Vol. 1, n. 1 (jan./jun. 2011) - Santo André, SP: FAINC, 2011.

MARTIANI, L. A. O vídeo e a pedagogia da comunicação no ensino universitário. In: PENTEADO, H.L. Pedagogia da comunicação - Teorias e Práticas. Ed. Cortez, 1998. p. 151 $-195$.

MORAN, J. M. O vídeo na sala de aula. Comunicação e educação. São Paulo, v.1, n.2, p. 27-35, Jan./abr. 1995.

NEWMAN, R. S. Adaptive help-seeking: A role of social interaction in self-regulated learning. In S. A.Karabenick (Ed.), Strategic help seeking: Implications for learning and teaching (pp. 13-37). Hillsdale, NJ: Erlbaum. 1998

PERRENOUD, P. Avaliação: da excelência à regulação das aprendizagens: entre duas lógicas. Porto Alegre: Artmed, 1999. 
QUADROS, Ronice Muller de, KARNOPP, Lodenir Becker. Língua de Sinais Brasileira: Estudos linguísticos. Porto Alegre: Artmed, 2004.

REVISTA DA FENEIS. Números 1 ao 13. R.J. 1999/2002.

REYNA, C. P. Vídeo e pesquisa antropológica: encontros e desencontros. Biblioteca online de Ciências da Comunicação. 1997.

SILVA, G.M. Parâmetros da Libras. Universidade Federal de Minas Gerais. Ed. Belo Horizonte. 2007

SILVA, Janssen Felipe da. Avaliação na perspectiva formativa-reguladora: pressupostos teóricos e práticos. Porto Alegre: Mediação, 2004.

SIMÃO, A. Aprendizagem estratégica: uma aposta na auto-regulação. Lisboa: Ministério da Educação, 2002.

VASCONCELLOS, Celso. Avaliação: concepção dialética libertadora do processo de avaliação escolar. 15. Ed. São Paulo: Libertad, 2005.

Recebido em 05 de Abril de 2017 Aprovado em 28 de Agosto de 2018 